\title{
Mosca-Negra-dos-Citros: Características Gerais, Bioecologia e Métodos de Controle dessa Importante Praga Quarentenária da Citricultura Brasileira
}

\author{
Anderson Gonçalves da Silva ${ }^{\circledR}$, Paulo Roberto Silva Farias², Arlindo Leal Boiça Junior ${ }^{1}$ \& \\ Bruno Henrique Sardinha Souza
}

1. FCAV/UNESP - Jaboticabal-SP, e-mail: agroanderson.silva@yahoo.com.br (Autor para correspondência ${ }^{\bowtie}$ ), aboicajr@fcav.unesp.br, souzabhs@gmail.com.2. Universidade Federal Rural da Amazônia (UFRA), e-mail: paulo.farias@pq.cnpq.br.

EntomoBrasilis 4 (3): 85-91 (2011)

Resumo. A mosca-negra-dos-citros, Aleurocanthus woglumi Ashby, é uma séria praga da cultura dos citros e de outras frutíferas de importância econômica. Constitui-se praga quarentenária presente ou A2 de alerta máximo, restringindo o comércio com outras regiões livres de sua presença. A partir de sua primeira ocorrência, no ano de 2001 na cidade de Belém, houve sua rápida disseminação para outros estados e regiões citrícolas do Brasil. Por ser uma praga exótica, conhecimentos básicos são escassos para se implementar o manejo adequado do inseto em território brasileiro. Desse modo, o objetivo do presente estudo é o de disponibilizar informações a respeito de aspectos importantes de A. woglumi, como: histórico e distribuição geográfica, bioecologia, plantas hospedeiras, métodos de controle adotados, dentre outros, a fim de se fornecer subsídios para futuras pesquisas sobre a mosca-negra-dos-citros no Brasil.

Palavras-Chave: Aleurocanthus woglumi; Aleyrodidae; Citrus sinensis

\section{Citrus Blackfly: General Aspects, Bioecology and Methods for the Control of this Important Quarantine Pest to Brazilian Citrus Production}

Abstract. Citrus blackfly, Aleurocanthus woglumi Ashby, is a serious pest of citrus culture and other economically important fruit crops. It is a present quarantine pest or A2 maximum alert restricting trades with other regions free of its presence. Since the first occurrence of the citrus blackfly in Belém in 2001 its dissemination was quickly to other States and regions of citrus production in Brazil. As an exotic pest, basic knowledge is scarce in order to establish the appropriate management to the insect in Brazil. Thus, the aim of the present study was to provide information about important aspects of $A$. woglumi, such as: history and geographical distribution, bioecology, host plants, appropriate control methods, among others, in order to provide subsidies for futures researches about the citrus blackfly in Brazil.

Keywords: Aleurocanthus woglumi; Aleyrodidae; Citrus sinensis

A mosca-negra-dos-citros, Aleurocanthus woglumi Ashby (Hemiptera: Sternorrhyncha: Aleyrodidae) é uma séria praga da cultura dos citros e de outras frutíferas de importância econômica; constitui-se praga quarentenária presente ou A2 de alerta máximo, restringindo o comércio com outras regiões livres de sua presença (MAPA 2011a). Em geral, nos países onde ocorre, pode causar de 20 a $80 \%$ de perdas na produção (Oliveira et al. 2001), afetando assim a produção agrícola e as exportações, não apenas de citros como a de outras fruteiras. A partir de sua primeira ocorrência, no ano de 2001 na cidade de Belém (Silva 2005), houve sua rápida disseminação para outros estados e regiões citrícolas do Brasil.

De acordo com Lopes et al. (2009), os impactos negativos decorrentes da introdução da mosca-negra-dos-citros em regiões produtoras de frutas pode ter consequências desastrosas, não somente do ponto de vista econômico, mas, também, ambiental, devido aos efeitos que as medidas de controle adotadas podem ter sobre os recursos naturais quanto ao dano da praga na flora nativa, e ainda à sua possível adaptação a outras espécies comerciais, no momento não consideradas hospedeiras.

Por ser uma praga exótica, conhecimentos básicos são escassos para se implementar o manejo adequado da mesma em território brasileiro. Desse modo, o objetivo do presente estudo é de disponibilizar informações a respeito de aspectos importantes do A. woglumi como: histórico e distribuição geográfica, bioecologia, plantas hospedeiras, métodos de controle adotados, dentre outros, a fim de dar subsídios para futuras pesquisas sobre essa importante praga quarentenária.

\section{HISTÓRICO E DISTRIBUIÇÃO GEOGRÁFICA}

A mosca-negra-dos-citros, A. woglumi, é nativa da Ásia e foi primeiramente descrita em 1915 (CLAUSEN 1978). Apresentase amplamente distribuída geograficamente só não tendo relatos de sua ocorrência em regiões do continente Europeu e nos pólos (HART et al. 1978; EPPo 1997), apresentando nomes vulgares como: mosca-negra-dos-citros ou somente mosca negra, mosca negra de los cítricos, mosca prieta, citrus blackfly e spiny citrus whitefly (Dowell \& FitzPATRICK 1978).

É uma das 69 espécies de aleirodídeos do gênero Aleurocanthus. Destas 29 são encontradas no Oriente (China, Índia e sudeste Asiático), 23 na África e 17 na Austrália, na região do Pacífico. Ás únicas espécies largamente disseminadas são A. woglumi e Aleurocanthus spiniferus (Quaintance), ambas intimamente associadas ao citros (Dowell et al. 1981).

A mosca negra é uma séria praga dos citros, originária do Sudeste Asiático encontrando-se disseminada em regiões tropicais e subtropicais da África, Índia Ocidental, Américas 
Central, do Norte, do Sul (Heu \& Nagamine 2001) e Oceania (COSAVE 1999).

Foi primeiramente descrita no hemisfério ocidental na Jamaica em 1913, sendo em seguida relatada em Cuba 1916; Estados Unidos em 1934 (Flórida, Havaí e Texas), no México em 1935; na República Dominicana em 1969, e Guiana Francesa em 1995 (MARTIN 1999). Atualmente tem sido detectada em todas as zonas citrícolas da Venezuela onde sua primeira ocorrência se deu em 1965 (MARTinÉz 1982). Na América do Sul a mosca-negrados-citros é encontrada também na Colômbia, Equador, Guiana, Peru e Suriname (COSAVE 1999).

Sua primeira ocorrência no Brasil foi relatada no estado do Pará, em 16 de maio de 2001, em jardins da cidade de Belém. A entrada da praga somente neste ano, considerando a presença da mesma na Jamaica desde 1913 e Venezuela 1965, se credita à barreira natural formada pela floresta amazônica que se constitui grande obstáculo à introdução natural de pragas oriundas das Américas Central e do Norte (Silva 2005).

O Maranhão foi o segundo estado brasileiro a relatar a presença de mosca-negra-dos-citros, em 15 de setembro de 2003, nos municípios de Imperatriz e Bacabal (Lemos et al. 2006). Hoje a praga se encontra presente nos estados do Amapá (JorDão \& Silva 2006), Amazonas (Pena \& Silva 2007), Tocantins e Goiás (MAPA 2011a).

No estado de São Paulo, principal produtor citrícola, houve o primeiro relato de sua ocorrência em 10 de março de 2008, no município de Arthur Nogueira, atacando laranjeiras das variedades Westin, Hamlin e Pêra; além de outras espécies frutíferas como abacateiro, goiabeira, bananeira e caquizeiro. Detectou-se também a ocorrência de mosca-negra-dos-citros nos municípios de Cosmópolis, Paulínia, Engenheiro Coelho e Limeira (PENA et al. 2008).

Em Janeiro de 2010 a mosca-negra-dos-citros teve seu primeiro relato no estado da Paraíba, já estando disseminada por mais de 15 municípios paraibanos. Suspeitas de sua ocorrência em municípios do Vale do Sirijii em Pernambuco vem causando preocupação por parte dos produtores do Vale do São Francisco. Tal fato se deve, pois essa importante região está inserida numa Área de Proteção Fitossanitária, e representa mais de 90\% das exportações brasileiras de manga e uva, frutíferas que estão entre as mais de 300 plantas hospedeiras ameaçadas pela praga, e caso registre seu primeiro relato, poderá sofrer sansões por parte dos principais importadores como EUA, Japão e Europa (LOPEs et al. 2009). Informações pessoais também dão conta da presença da praga no estado de Roraima.

A partir de sua primeira ocorrência, no ano de 2001 na cidade de Belém, houve uma rápida disseminação da moscanegra-dos-citros para outros estados e regiões citrícolas do Brasil. Presume-se que o comércio através de transporte via fluvial e, principalmente o rodoviário, foi o maior facilitador desta rápida disseminação, devido principalmente, ao transporte de frutos de laranja in natura de áreas de ocorrência da praga para indústrias de suco concentrado no Estado de São Paulo, tendo em vista que 90\% da produção paraense é exportada principalmente para o estado paulista (para indústria de suco) e para o Nordeste brasileiro (consumo in natura). Dessa forma, o transporte ao longo das rodovias, aliado a deficiência de fiscalizações, tenham sido o maior facilitador da disseminação dessa praga para os principais estados citricultores brasileiros.

Importância econômica

Na cultura dos citros a mosca negra acarreta danos diretos e indiretos prejudicando o desenvolvimento e produção de pomares cítricos, como em outras culturas de expressiva importância econômica. Além de restringir o comércio de locais de sua ocorrência para áreas livres da presença da praga, o $A$. woglumi é considerado praga quarentenária presente (A2) de alerta máximo de acordo com a instrução normativa $\mathrm{n}^{\circ} 23$, de 29 de abril de 2008; estabelecida pelo Ministério da Agricultura, Pecuária e Abastecimento (MAPA).

Os danos diretos ocasionados pela mosca-negra-doscitros são decorrentes da sua alimentação diretamente no floema da planta (Figura 1) retirando destas nutrientes debilitando-as, além de injetar toxinas presentes em sua saliva. De forma indireta, e, mais prejudicial, elimina secreção açucarada que induz ao aparecimento de fungos saprófitos que formam a fumagina (Campinodium citri Berk \& Desm.) (OliveIra et al. 1999) (Figura 2). Estes, embora não sejam parasitas, pelo seu crescimento escuro e denso, podem reduzir consideravelmente quantidade de luz que incide sobre os órgãos clorofilados da planta, reduzindo a capacidade de fotossíntese dos mesmos (CunHA 2003). A ocorrência na sua face inferior pode também interferir com as trocas gasosas que se dão através dos estômatos. Do ponto de vista econômico, a fumagina pode prejudicar a qualidade dos produtos agrícolas, alterando a sua aparência depreciando o fruto para a comercialização in natura.

Em médias e altas infestações, as folhas se tornam negras na face abaxial e adaxial (Figuras 1 e 2), devido às ninfas e a fumagina, respectivamente. Vários produtos orgânicos podem ser removidos pela sucção dos insetos e o teor de nitrogênio $(\mathrm{N})$ é um indicativo disso. Cerca de 5 a 10 ninfas por centímetro quadrado são suficientes para reduzir o nível de nitrogênio abaixo dos 2,2\% necessários para boa frutificação em laranja (CuNHA 2003). Trabalhos conduzidos no México dão conta de que mais de $90 \%$ da redução na produção de frutos ocorre quando as infestações excedem 5 a 7 ninfas/ $\mathrm{cm}^{2} /$ folha. De 50 a 100 ninfas por folha são necessárias para redução dos níveis de $\mathrm{N}$ para abaixo de $2,2 \%$ (Summy et al. 1983).

Em geral, nos países onde ocorre, a mosca negra pode causar de 20 a $80 \%$ de perdas na produção, afetando assim a produção agrícola e as exportações, não apenas de citros como a de outras fruteiras (Oliveira et al. 2001). Quando o ataque severo se dá nas plantas ainda novas ou em fase de mudas, pode levá-las à morte (PARKINSON \& SEALES 2000).
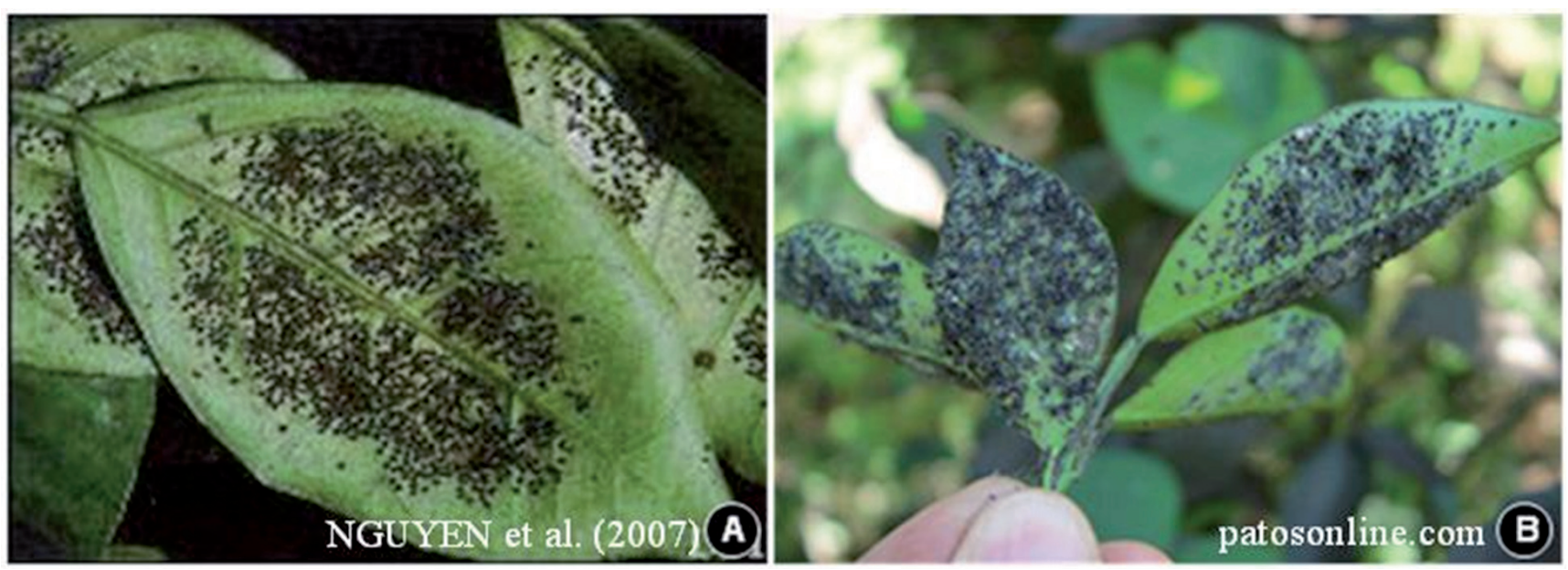

Figura 1. (A) Folha infestada e (B) ramo infestado por mosca-negra-dos-citros, A. woglumi. 


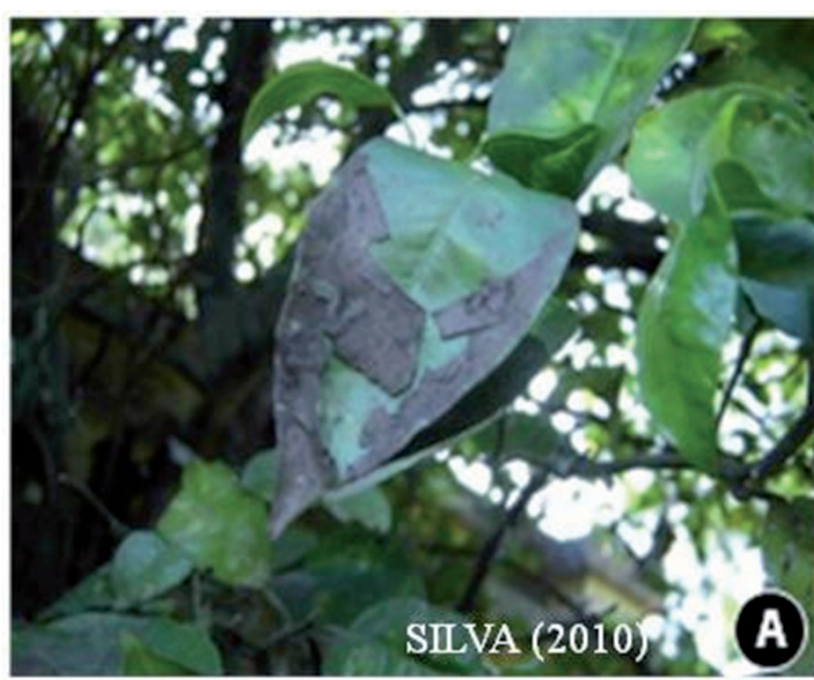

Figura 2. (A) Folha e (B) fruto cobertos por fumagina, C. citri.

\section{DESCRIÇÃO E BIOECOLOGIA}

A mosca-negra-dos-citros é um inseto picador sugador da Ordem Hemiptera, Subordem Sternorrhyncha, Família Aleyrodidae, podendo ser encontrada na literatura apresentando ás seguintes sinonímias: Aleurocanthus punjabensis Corbett, Aleurocanthus husain Corbett e A. woglumi. O inseto adulto (Figura 3) apresenta asas de cor acinzentada com reflexos metálicos, devido às ceras que as recobrem. O corpo é vermelhoalaranjado apresentando pernas e antenas esbranquiçadas. $\mathrm{O}$ sexo é facilmente diferenciado pelo tamanho, pois o macho mede o,9 mm de comprimento enquanto a fêmea mede 1,3 mm (NGUYEN et al. 2007). Ás asas anteriores, além da cor escura predominante, têm pequenas manchas pontuais na região mediana e uma linha transversal na parte final (Silva 2005).

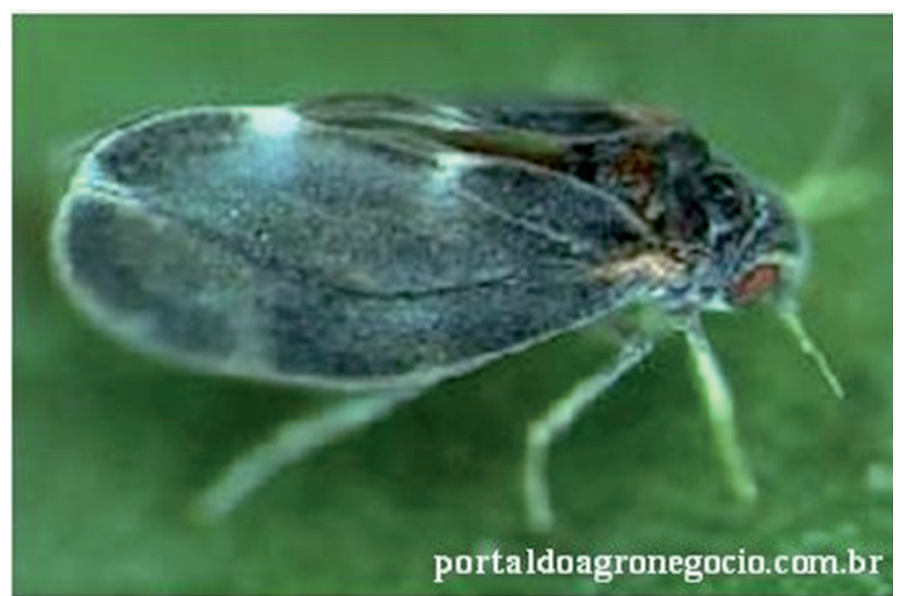

Figura 3. Adulto de mosca-negra-dos-citros, A. woglumi.

Os ovos apresentam forma oval, alongado, reniforme e pedicelado; medindo cerca de o,2 $\mathrm{mm}$ de comprimento. Logo após a postura apresentam coloração de um amarelo-claro translúcido, tornando-se marrons e negros à medida que o embrião se desenvolve (Rossato 2007). São colocados em forma de espiral na parte abaxial da folha (Figura 4). Cada fêmea coloca dois a três espirais de ovos durante sua vida, que varia de 10 a 14 dias. Sendo que em cada postura são colocados de 35 a 50 ovos (EPPo 1997).

A reprodução é sexuada com oviparidade, mas pode ocorrer partenogênese. Após a eclosão das ninfas, essas ficam aderidas à face inferior das folhas apresentando desenvolvimento rápido, ocorrendo quatro ecdises caracterizadas por uma fase que não se locomove e nem se alimenta denominada ninfa IV ou "pupário" (Figura 4), antes de emergir o adulto (Gallo et al. 2002).

Segundo estudos de NGUYEN et al. (2007) para aspectos

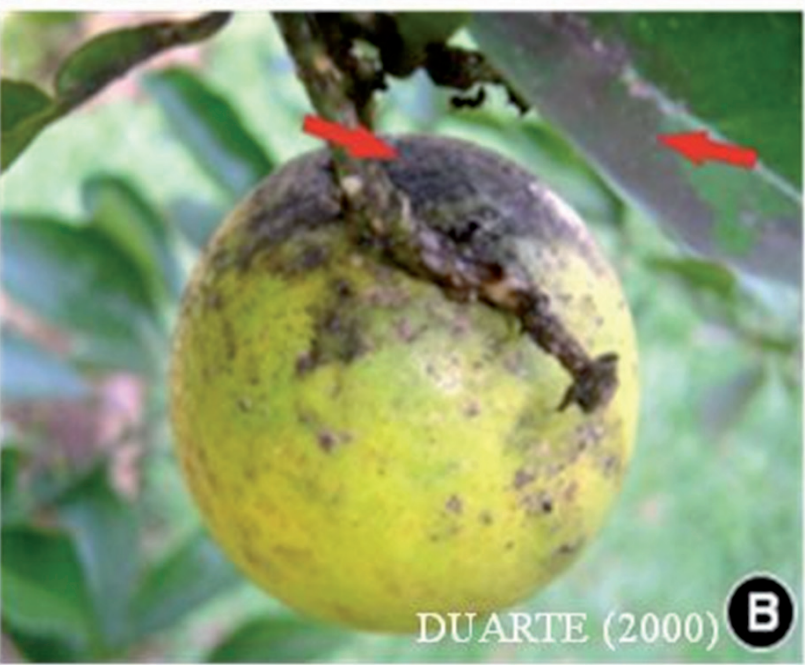

morfológicos da fase imatura de $A$. woglumi, observou-se que os ovos eclodem dentro de 7 a 10 dias, com o primeiro instar apresentando duração de 7 a 16 dias. O segundo instar de coloração marrom escuro, com numerosos espinhos que cobrem o corpo todo, apresenta duração de 7 a 30 dias. O terceiro instar apresenta a coloração negra com espinhos mais resistentes e numerosos e mais brilhantes do que aqueles do segundo instar, apresentando duração de 6 a 20 dias. A ninfa de quarto instar é brilhante, com uma listra marginal de cera branca e o estágio de "pupa” que dura de 16 a 50 dias (Figura 4).

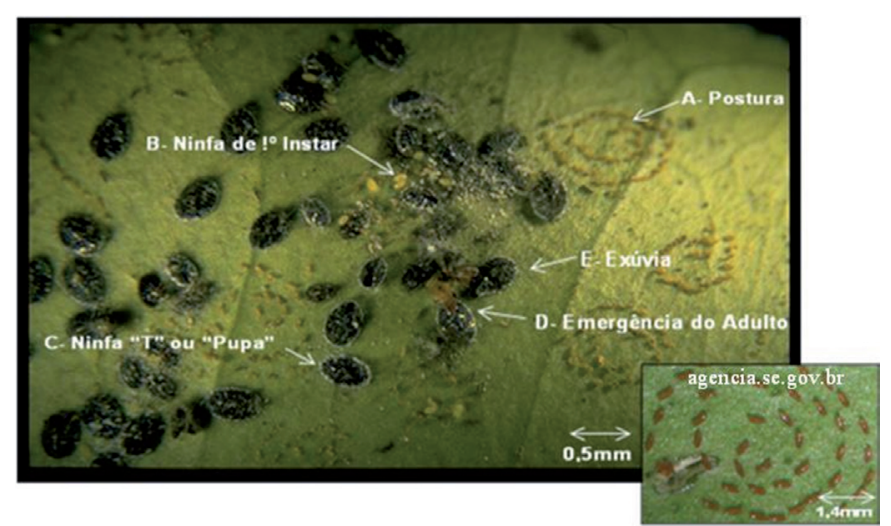

Figura 4. (A) Postura, (B) ninfa de $1^{\mathrm{O}}$ instar, (C) ninfa "T" ou "pupa", (D) emergência do adulto e (E) exúvia de mosca-negra-dos-citros, $A$. woglumi. Em destaque postura em forma de espiral.

De acordo French et al. (2005), o adulto emerge da abertura da pupa em forma de "T". O tempo para a emergência normal é de 14 a 30 minutos. A completa expansão das asas pode levar de 18 a 30 minutos. Na emergência o inseto possui a cabeça de coloração amarelo pálido. Os pés são esbranquiçados e os olhos são marrom-avermelhados. Dentro de 24 horas após a emergência, o inseto é coberto com um pó fino da cera que lhe dá uma aparência azulada (NGuYen et al. 2007). Podem viver em média 14 dias, com praticamente toda oviposição completada nos primeiros 4 dias após a emergência.

Embora a fecundidade máxima seja de 100 ovos, a média é de 65 a 70 . Fêmeas não fecundadas podem pôr ovos viáveis que produzem apenas machos através de paternogênese arrenótoca (MEAgher et al. 1991). A razão sexual é de um macho para uma fêmea (CHerry \& FitzPatrick 1979) e em áreas infestadas pode-se encontrar uma média de 772 pupas por folha (Oliveira et al.1999). De acordo com DreEs \& JACKMAN (1998) o desenvolvimento completo ocorre entre 60 a 120 dias, dependendo da temperatura.

Na região amazônica a mosca-negra-dos-citros encontra condições ideais de desenvolvimento, ou seja, temperatura entre 28 e $32^{\circ} \mathrm{C}$ e umidade relativa de 70 a $80 \%$ (Silva 2005); nessas 
mesmas condições, Silva et al. (2011a) e Silva et al. (2011b), observaram que a temperatura é um importante fator abiótico influenciando na regulação da população de mosca-negra-doscitros. Estudos efetuados por CUNHA (2003) mostraram que o inseto apresenta ciclo evolutivo bastante rápido no estado do Pará, chegando a apresentar de 5 a 6 gerações anuais, observando-se também o efeito da sobreposição de gerações. Este autor afirma também que o número médio de ovos por postura é de 26 a 58, com amplitude de 7 a 48 dias e que o número de adultos gerado por um casal ao fim de um ano foi de 1845 .

A mosca negra não sobrevive em temperaturas em torno de $40^{\circ} \mathrm{C}$ e altitudes acima de 1000m (Oliveira et al. 1999). Chuva, vento e baixa umidade são fatores ambientais importantes para a praga (Dowell et al. 1981). FLANDERS (1969) verificou que ventos fortes e chuvas pesadas mostraram-se capazes de desalojar e matar adultos da praga, fato corroborado por MAIA (2008); Medeiros et al. (2009) e Silva et al. (2011a), que relataram que a população de $A$. woglumi é bastante reduzida devido a maior precipitação pluviométrica.

\section{PLANTAS HOSPEDEIRAS}

A mosca negra apresenta mais de 300 plantas hospedeiras (Oliveira et al. 1999), dentre elas plantas cultivadas, ornamentais e daninhas; porém ocorre principalmente em plantas do gênero Citrus (DreEs \& JACKMAN 1998). Merecendo maior atenção, de acordo com a recente instrução normativa $\mathrm{n}^{0}$ 23, de 29 de abril de 2008, ás seguintes plantas: Abacate (Persea americana Mill.), Álamo (Populus spp.), Amora (Morus spp.), Ardisia (Ardisia swartz Swartz.), Bananeira (Musa spp.), Buxinho (Buxussem pervirens Sabamiki), Café (Coffea arabica L.), Caju (Anacardium occidentale L.), Carambola (Averrhoa carambola L.), Cherimóia (Annona cherimola Mill.), Dama da noite (Cestrum nocturnum Linn.), Gengibre (Zingiber officinale Roscoe), Goiaba (Psidium guajava L.), Graviola (Annona muricata L.), Grumixama (Eugenia brasiliensis Lam.), Hibisco (Hibiscus rosasinensis L.), Jasmim-manga (Plumeria rubra L.), Lichia (Litchi chinensis Sonn.), Louro (Laurus nobilis L.), Mamão (Carica papaya L.), Manga (Mangifera indica L.), Maracujá (Passiflora edulis Sims.), Marmelo (Cydonia oblonga Mill.), Murta (Murraya paniculata (L.) Jack.), Pêra (Pyrus spp.), Pinha (Annonas quamosa L.), Romã (Punica granatum L.), Rosa (Rosa spp.), Sapoti (Manilkara zapota L.) e Uva (Vitis vinifera L.) (MAPA 2011a).

\section{DISPERSÃO DE $A$. woglumi}

A dispersão de A. woglumi se dá verticalmente na planta e horizontalmente entre plantas. Ocorrendo principalmente de forma antrópica através de mudas ou plantas ornamentais infestadas transportadas pelohomem epodeocorrer naturalmente através de folhas infestadas carregadas pelo vento ou dispersão natural pelo crescimento populacional da praga (SiLva 2005).

Estudos de Sılva (2010); avaliando a distribuição espacial do $A$. woglumi em sistemas de plantio agroflorestal e monocultura utilizada a metodologia geoestatística, observaram que a distribuição espacial da mosca negra dáse, predominantemente, em agrupamentos com dependência espacial descrita pelo modelo esférico, formando reboleiras de 8,5 a 34m (alcance do modelo) para ambos os sistemas de plantio adotados. Resultados semelhantes foram obtidos por MAIA (2008) em estudo em plantio de citros em sistema convencional na Região Amazônica.

Segundo Dowel \& FitzPatrick (1978) a mosca negra é capaz de se deslocar cerca de 400 a 600 metros por geração sem ajuda humana e os insetos individuais podem se distanciar de sua planta de origem até 50 metros por dia. Oliveira et al. (2001) observou que essa dispersão horizontal através do voo pode chegar a 187 metros em $24 \mathrm{~h}$, e segundo estimativas teóricas a disseminação natural da praga se dá a uma velocidade de 200 a $300 \mathrm{~km}$ por ano, principalmente ao longo das rodovias (SiLva
2005).

No entanto há unanimidade entre os cientistas em definir o transporte de plantas (mudas) como o principal meio de dispersão da praga. Estudos de French \& MEagher (1992) relataram a emergência de adultos a partir de ninfas de quarto instar em folhas retiradas da planta há 12 dias e armazenadas em ambiente refrigerado. Estes autores observaram também que em condições de packing house, todos os adultos eclodiram em folhas de até quatro dias após o corte; e, essas folhas quando aspergidas em água e colocadas e um saco plástico, ás emergências podem atingir a taxa de $19 \%$ em até 13 dias.

\section{INSPEÇÃO E MONITORAMENTO}

Os focos iniciais da mosca-negra-dos-citros costumam ocorrer em áreas urbanas, em pequenos grupos e árvores isoladas. De acordo com Dowell et al. (1981), as armadilhas amarelas podem indicar a presença onde a inspeção visual não foi suficiente. A literatura aponta três diretrizes gerais para as inspeções de detecção de mosca negra: 1) CherRy \& FitZPATRICK (1979) indicam como áreas preferenciais para a presença de infestações a metade inferior da planta; 2) Dowell et al. (1981) concluíram que os ovos de A.woglumi costumam estar agrupados nas folhas e estas, por sua vez, compõem grupos de folhas infestadas; 3) em níveis de controle, a mosca negra é facilmente percebida por estar sempre associada à presença de fumagina.

Para fazer o monitoramento da mosca-negra-dos-citros é importante observar a presença de fungos, inspecionando também a parte abaxial das folhas para observação de ninfas e pupas. As armadilhas amarelas adesivas podem ser usadas como atrativos aos adultos de $A$. woglumi, dando um indicativo do tamanho da população. A ausência de populações de parasitóides e predadores visíveis, aliado a um aumento da população da praga pode indicar a necessidade de tratamentos com inseticidas no pomar (FRENCH 2001).

Na região do Texas EUA, o monitoramento da moscanegra-dos-citros consiste no uso integrado das tecnologias do sistema de posicionamento global (GPS), sistema de informação geográfica(SIG)eSensoriamentoRemoto, esteconsisteem mapear ás áreas com presença do fungo fumagina correlacionando-a com infestações da mosca negra, com posterior controle das infestações da praga (focos) in loco (EveritT et al.1994; FLETHER et al. 2004).

MaIA (2008) elaborou um plano de amostragem sequencial (presença/ausência) para o monitoramento do $A$. woglumi. Basicamente este consiste em percorrer a área a ser amostrada aleatoriamente ou em zigue-zague e observar se há presença de ninfa ou adulto de $A$. woglumi em cada planta avaliada. A seguir o número de plantas infestadas a cada 10 plantas é acumulado a cada unidade amostrada. O valor acumulado é comparado com as linhas de decisão, optando-se por controlar ou não. Se o valor acumulado permanecer entre valores intermediários, deve-se continuar a amostragem até atingir o número máximo esperado de unidades amostrais para a tomada de decisão, quando se suspende a amostragem, devendo repeti-la antes da próxima amostragem programada.

\section{MÉTODOS DE CONTROLE DE MOSCA-NEGRA-DOS-CITROS}

Controle Cultural. Baseia-se em molhar as linhas de plantio, com água ou óleo, a fim de se evitar poeira nas folhas, favorecendo o desenvolvimento dos inimigos naturais da praga; manter as barreiras naturais de vento como proteção; manter o cultivo seguindo os cuidados de fertilização, drenagem e outros tratos culturais; comprar somente mudas com garantia dos órgãos competentes, além de podar e queimar ramos e galhos atacados pela praga (FRENCH \& MEAGHER 1992).

Controle Químico. Segundo Heu \& Nagamine (2001), embora as 
aplicaçõesdeinseticidaspossamajudarareduzirtemporariamente as infestações de mosca negra, esta tática de controle não é recomendada devido os perigos ao meio ambiente, aos animais, aos inimigos naturais e ao próprio homem. A aplicação de óleo comercial fino se constitui como meio de controle menos tóxico aos inimigos naturais. Deve-se notar que mesmo controlando quimicamente ou biologicamente os estágios imaturos do $A$. woglumi, estes continuaram unidos às folhas. Os resultados de um bom controle serão observados com o posterior crescimento da planta. É importante que se mantenham as plantas atacadas saudáveis através do fornecimento adequado de água e adubação para que a planta recupere os nutrientes perdidos pela infestação de mosca negra. É importante ressaltar que o controle químico é raramente utilizado mundialmente (NGUYEN et al. 2007).

Por se tratar de uma praga exótica, recém introduzida no Brasil, até o ano de 2007 não existia produto inseticida para o controle de A. woglumi registrado no Ministério da Agricultura, Pecuária e Abastecimento (MAPA). Com o primeiro relato de mosca-negra-dos-citros, no principal estado citricultor do Brasil, no inicio de 2008, esforços foram feitos para evitar a disseminação da mesma, nos pomares citrícolas do estado de São Paulo e hoje três produtos apresentam registro para o controle da praga. Kohinor 200 SC e Provado 200 SC, de grupo químico dos neonicotinóides, apresentando o imidacloprid como ingrediente ativo. Também com registro o Ampligo pertence ao grupo químico dos chlorantraniliprole (antranilamida) + lambda-cialotrina (piretróide) (MAPA 2011b).

Controle Biológico. A mosca-negra-dos-citros apresenta diversos inimigos naturais, com destaque para os microhimenópteros Amitus hesperidum Silvestri e Encarsia opulenta Silvestri, cujo controle biológico é amplamente utilizado mundialmente (NGUYEN et al. 1983). Segundo os mesmos autores, a fêmea do $A$. hesperidum parasita todos os três instares larvais da mosca negra com uma preferência para o primeiro, apresentando desenvolvimento sincronizado com o do seu hospedeiro. Cada parasitóide fêmea pode produzir até 70 proles em quatro a cinco dias com os hospedeiros adequados disponíveis. Entretanto, por ter ciclo de vida curto, apresenta sua eficiência de procura reduzida no parasitismo da mosca negra. Este parasitóide é mais eficaz com populações elevadas, especialmente durante estações de temperatura amena e de umidade elevada.

O micro-himenóptero $E$. opulenta apresenta taxa mais baixa da reprodução comparada ao A. hesperidum, no entanto, apresenta maior mobilidade relacionada à procura pela praga. As fêmeas desse parasitóide podem sobreviver até seis semanas. Geralmente, o E. opulenta pode manter uma população de mosca negra em um nível mais baixo do que $A$. hesperidum. As fêmeas de $E$. opulenta colocam um único ovo diplóide em todo o estágio larval do hospedeiro, embora o segundo estágio pareça preferível. No campo, a relação é de um macho para sete fêmeas (NGUYEN et al. 1983).

Segundo French et al. (2005) o número, a posição e a forma dos furos de saída do pupário identificam a espécie que se formou dentro da pupa de $A$. woglumi. Uma maneira simples de verificar se está havendo parasitismo é através da observação das exúvias (pupas) da mosca-negra-dos-citros, com auxílio de lupa de aumento de 10 a 20 vezes. Abertura da pupa se em forma de "T" indica a emergência do $A$. woglumi, abertura única em forma de círculo mostra a emergência de E. opulenta e a pupa com duas aberturas circulares significa a emergência da vespinha A. hesperidum.

De acordo com MARTINÉz et al. (1979) outros organismos também exercem importante papel no controle biológico de $A$. woglumi, como os predadores: Azya trinitatis Marshall, Pentilia castanea Mulsant, Azya sp., Curinus sp., Delphastus sp., Diomus sp. e Stethorus sp., provavelmente Mantispilla viridis Walker e os crisopídeos Chrysopa sp. e Nodita sp. Os parasitóides Cales sp., Prospaltella sp. e Eretmocerus sp. O controle microbiano é citado para os fungos entomopatogênicos: Aegerita webberi Fawcett e Aschersonia aleyrodis Webber. Também a registros de um díptero da família Syrphidae como um importante inimigo natural da mosca-negra-dos-citros.

Em Belém verificou-se um bom controle de A. woglumi pelo parasitismo de microvespas ainda não identificadas. Com relatos de parasitismo da ordem de 90\% (Silva 2005). Rossato (2007) estudando a ocorrência de parasitóides de A. woglumi nos municípios de Belém, Capitão Poço e Irituia no estado do Pará, observou que os himenópteros Encarsia sp. e Cales noacki Howard, mostraram-se presentes nos três municípios estudados e que $C$. noacki é um eficiente parasitóide de mosca-negra-doscitros nesses municípios paraenses.

Entre os predadores, nas condições amazônicas, temse destacado o bicho lixeiro (Ceraeochrysa cubana Hagen) que passou a se alimentar intensamente das ninfas de mosca negra, pois sua carcaça de exúvias, que normalmente era clara, passou a ser negra nos laranjais de Capitão Poço - PA, devido ás exúvias negras da praga do qual se alimentou (Silva 2005).

Quanto ao controle microbiano, verificaram-se no estado do Pará em pomares citrícolas os fungos entomopatogênicos $A$. aleyrodis, A. webberi e Fusarium sp. sobre ninfas de moscanegra-dos-citros. No estado de São Paulo, o Instituto Biológico detectou, no município de Artur Nogueira, a presença do fungo A. aleyrodes atacando ninfas de A. woglumi em condições favoráveis de epizootia (RAGA \& CosTA 2008).

\section{Situaçãolegislativa da mosca-negra-dos-citros no Brasil.} A mosca-negra-dos-citros é considerada uma praga quarentenária presente (A2), de acordo com a instrução normativa $\mathrm{n}^{\circ} 23$, de 29 de abril de 2008, que substituiu a Instrução Normativa SDA $n^{0}$ 20, de 21 de fevereiro de 2002. Esta se classifica como sendo uma praga de importância econômica potencial, já presente no país, porém não se encontram amplamente distribuída, possuindo programa oficial de controle.

Em resumo, dentre as principais restrições Impostas para o transporte e comercialização de produtos oriundos e/ ou espécies hospedeiras de Unidades da Federação onde seja constatada, por laudo laboratorial, a presença de $A$. woglumi para Unidades da Federação reconhecida como livre pelo MAPA - Ministério da Agricultura, Pecuária e Abastecimento (MAPA 2011a), tem-se:

Transporte e comercialização de Mudas e Borbulhas somente com permissão de trânsito de vegetais (PTV) com declaração adicional "Não se observaram sinais de A. woglumi no local de produção durante os últimos seis meses e a partida foi inspecionada, encontrando-se livre da praga", e a carga deve estar lonada ou transportada em caminhão tipo baú para transitar por área de ocorrência de mosca-negra-dos-citros. Transporte e comercialização de Frutas somente com permissão de trânsito de vegetais (PTV) com declaração adicional "Os frutos foram submetidos a processo de seleção para retirada de folhas e partes de ramos e a partida encontra-se livre de A. woglumi" (MAPA 2011a).

Em unidades da federação reconhecidas como livre da mosca negra, deverá ser realizado levantamentos semestrais de detecção e os relatórios decorrentes deverão ser enviados, por correspondência impressa, ao órgão de sanidade vegetal da Superintendência Federal de Agricultura, a fim de comprovar a ausência da praga no Estado. Às suspeitas ou constatações de ocorrência da mosca-negra-dos-citros deverão ser notificadas imediatamente ao órgão de sanidade vegetal da Superintendência Federal de Agricultura na UF correspondente. E o material apreendido pela fiscalização de defesa sanitária vegetal, em desacordo com o previsto nesta Instrução Normativa, será sumariamente destruído, não cabendo ao infrator qualquer tipo de indenização, sem prejuízo das demais sanções estabelecidas pela legislação vigente (MAPA 2011a).

Apesar de sua classificação datar de 1915, e muitos estudos já terem sido feitos em âmbito mundial, pouco se conhece do comportamento da mosca-negra-dos-citros em território brasileiro. Sendo esses, principalmente, nas regiões que primeiro detectaram a presença da praga como os Estados do Pará, 
Maranhão e Amazonas. Dessa forma, esforços devem ser feitos a fim de gerar conhecimentos que subsidiem a implementação de um programa adequado de manejo do $A$. woglumi. Disponibilizando para o agricultor métodos eficientes de controle e evitando assim que está importante praga se dissemine pelo território brasileiro.

\section{REFERÊNCIAS}

Cherry, R. \& G. Fitzpatrick, 1979. Intra-tree dispersion of citrus blackfly. Environmental Entomology, 8: 997-999.

Clausen, C.P., 1978. Biological control of citrus insects. In: Reuther, W., E.C. Calavan \& G.E. Carman. The citrus industry. Berkeley: University of California, 4: 276-320.

Cosave, 1999. Comite de sanidad vegetal del cone sur. Plagas cuarentenarias Aleurocanthus woglumi: hojas de datos sobre organismos cuarentenarios para los paises miembros del COSAVE. Disponível em: <http://www.cosave.org.py> Acesso em: 20 jan. 2011.

Cunha, M.L.A., 2003. Distribuição, hospedeiros, densidade populacional, aspectos biológicos e controle químico da mosca negra dos citros (Aleurocanthus woglumi Ashby) nas condições do Estado do Pará. Dissertação (Mestrado em Agronomia) - Universidade Federal Rural da Amazônia, Belém. 54p.

Dowell, R., V. Cherry, C. Fitzpatrick, J. Reinert \& J. Knapp, 1981. Biology plant insect relations and control of the citrus blackfly. Gainesville: Agricultural Experimental Station, (Thecnical Bulletin, 818), 49p.

Dowell, R. \& C. Fitzpatrick, 1978. Effect of temperature on the growth and survival of the citrus blackfly. Canadian Entomologist, 110: 1347-1350.

Drees, B.M \& J.A. Jackman, 1998. A field guide to s ckçv Texas insects. Houston: Gulf Publishers, 359p.

Eppo, 1997. European and mediterranean plant protection organization. Aleurocanthus woglumi. p 25-29. In: Eppo. Quarantine Pests for Europe, 2. ed, Wallingford: $\mathrm{CAB}$ International.

Everitt, J.H., D.E. Escobar, K.R. Summy \& M.R Davis, 1994. Using airbone vídeo, global positioning system, and geographical information system technogies for detecting and mapping citrus blackfly infestations. Southwestern Entomology, 19: 129-138.

Flanders, S.E., 1969. Observations on citrus blackfly parasites in índia and México and correlated circunstances. Canadian Entomologist, 101: $467-480$.

Flether, R.S., J.H. Everitt, M.R. Davis \& D.E. Escobar, 2004. Integrating airbone imagery and GIS technology to map and compare citrus blackfly infestations occurring in different years. Horttechnology, 14: 398-401.

French, J.V. 2001. Texas Center pest control guide. Texas A \& M Citrus Center - Weslaco.

French, J.V. \& R.L. Meagher, 1992. Citrus blackfly: chemical control on nursery trees. Subtropical Plant Science, 45: 7-10.

French, J.V., D.S. Moreno, K.R. Summy, A.N.J.R. Sparks \& P.F. Lummus, 2005. Citrus Center. Texas A \& M University - Kingsville Citrus Center. Disponível em: <http://primera. tamu.edu/kcchome/webpages/cblkfly.htm >. Acesso em: 21 nov. 2009.

Gallo, D., O. Nakano, S. Silveira Neto, R.P.L. Carvalho, G.C. Batista, E. Berti Filho, J.P.R. Parra, R.A. Zucchi, S.B. Alves, J.D. Vendramin, L.C. Marchini, J.R.S. Lopes \& C. Omoto, 2002. Entomologia agrícola. Piracicaba, Fealq, 10: 49-52.

Hart, W.G., A. Selhime, D.P. Harlan, S.I. Ingle, R.M. Sanches, R.H. Rhode, C.A. Garcia, J. Caballero \& R.L. Garcia, 1978. The Introduction and Establishmento of Parasites of Citrus Blackfly, Aleurocanthus woglumi in Florida. (Hem.: Aleyrodidae). Entomophaga, 23: 361-366.

Heu, R.A. \& W.T. Nagamine, 2001. Citrus Blackfly Aleurocanthus woglumi Ashby (Homoptera: Aleyrodidae). New Pest Advisory, 99: 1-3
Jordão, A.L. \& R.A. Silva, 2006. Guia de pragas agrícolas para o manejo integrado no Estado do Amapá. Ribeirão Preto: Holos, $182 \mathrm{p}$.

Lemos, R.N.S., G.S. Silva, J.R.G. Araújo, E.F. Chagas, A.A. Moreira \& A.T.M. Soares, 2006. Ocorrência de Aleurocanthus woglumi Ashby (Hemiptera: Aleyrodidae) no Maranhão. Neotropical Entomology, 35: 558-559.

Lopes, E.B., I.C. Albuquerque, F.R. Costa \& J.A.M. Borges, 2009. Mosca-Negra-dos-Citros (Aleurocanthus woglumi Ashby) (Hemiptera: Aleyrodidae) Chega à Paraíba. AMEPA-PB, Empresa Estadual de Pesquisa Agropecuária da Paraíba; Estação Experimental de Lagoa Seca. (Relatório TécnicoFitossanitário), 17p.

Maia, P.S.P., 2008. Caracterização da distribuição espacial da mosca negra dos citros (Aleurocanthus woglumi Ashby, 1915) em pomar georreferenciado para determinar um plano de amostragem seqüencial. Dissertação (Mestrado); Universidade Federal Rural da Amazônia, Belém. 77p.

MAPA, 2011a. Ministério da Agricultura, Pecuária e Abastecimento. Lista de pragas quarentenárias presentes - (A2). Disponível em: <http://extranet.agricultura.gov. $\mathrm{br} /$ sislegis-consulta/servlet/VisualizarAnexo?id=14560 $>$. Acesso em: 10 set. 2011.

MAPA,2011b.MinistériodaAgricultura,PecuáriaeAbastecimento. AGROFIT: sistema de agrotóxicos fitossanitários. Disponível em: $\quad$ http://agrofit.agricultura.gov.br/agrofit cons/ principal agrofit cons $>$. Acesso em: 18 mar. 2011.

Martin, U., 1999. Citrus blackfly control in Dominica. Tropical Fruits Newsletter, 32: 3-6.

Martinéz, N.B., 1982. Biologia de la mosca prieta de los cítricos Aleurocanthus woglumi Ashby (Homoptera: Aleyrodidae) em el campo. Agronomia Tropical, 31: 211-218.

Martinéz, N.B, J.B. Terán \& F. Geraud, 1979. Enemigos Naturales de la Mosca Prieta de Los Cítricos Aleurocanthus woglumi Ashby (Homoptera: Aleyrodidae) en Venezuela. Agronomía Tropical, 29: 453-458.

Meagher, R.L., J.V. French \& K.L. Esau, 1991. Monitoring and biological control of citrus blackfly. Subtropical Plant Science, 44: 19-24.

Medeiros, F.R., R.N.S. Lemos, A.L.T. Ottati, J.R.G. Araújo, K.K.G. Machado \& A.A.C. Rodrigues, 2009. Dinâmica populacional da mosca-negra-dos-citros Aleurocanthus woglumi ashby (Hemiptera: aleyrodidae) em Citrus spp. no município de São Luís - MA. Revista Brasileira de Fruticultura, 31: 1016 $-1021$.

Nguyen, R., J.R. Brazzel \& C. Poucher, 1983. Population density of the citrus blackfly, Aleurocanthus woglumi Ashby (Homoptera: Aleyrodidae), and its parasites in urban Florida in 1979-81. Environmental Entomology, 12: 878-884.

Nguyen, R., A.B. Hamon \& T.R. Fasulo, 2007. Citrus blackfly, Aleurocanthus woglumi Ashby (Insecta: Hemiptera: Aleyrodidae). Florida Cooperative Extension Service, Institute of Food and Agricultural Sciences. University of Florida. 1-5. Disponível em:<http://edis.ifas.ufl.edu $>$. Acesso em: 16 jan. 2011.

Oliveira, M.R.V., C.C.A., Silva \& D. Navia, 2001. Mosca negra dos citros Aleurocanthus woglumi: alerta quarentenário. Brasília: Ministério da Agricultura, Pecuária e Abastecimento, 12p.

Oliveira, M.R.V., C.C.A., Silva \& D. Navia,1999. Praga Quarentenária A1: a mosca negra dos citros, Aleurocanthus woglumi Ashby (Hemiptera: Aleyrodidae). EMBRAPA, 7p. (Comunicado Técnico, 40).

Parkinson, K. \& J. Seales, 2000. Citrus blackfly, its presence and management in Trinidad and Tobago. Procaribe News, Network, 11p.

Pena, M.R. \& N.M. Silva, 2007. Sugadora negra. Revista Cultivar: hortaliças e Frutas. Pelotas, 41: 16-18.

Pena, M.R., J.D. Vendramim, A.L. Lourenção, N.M. Silva, P.T. Yamamoto \& M.S. Gonçalves, 2008. Ocorrência da moscanegra-dos-citros, Aleurocanthus woglumi Ashby (Hemiptera: Aleyrodidae) no estado de São Paulo. Revista Brasileira de 
Engenharia Agrícola e Ambiental, 83: 61 - 65.

Raga, A. \& V.A Costa, 2008. Mosca negra dos citros. Instituto Biológico - APTA. Documento Técnico - 1. Abril de 2008. 9 p. Disponível em:<http://www.biological.sp.gov.br $>$. Acesso em: 16 out. 2009.

Rossato, V., 2007. Ocorrência de Parasitóides de Aleurocanthus woglumi Ashby, 1903 (Hemiptera: Aleyrodidae) e seu Parasitismo por Cales noacki Howard, 1907 (Hymenoptera: Aphelinidae) nos Municípios de Belém, Capitão Poço e Irituia no Estado do Pará. Dissertação (Mestrado): Universidade Federal Rural da Amazônia, Belém. 39p.

Silva, A.B., 2005. Mosca negra dos citros, Aleurocanthus woglumi Ashby, praga potencial para a citricultura brasileira. p. 147 - 156. In: Poltronieri, L.S., D.R. Trindade \& I.P. Santos. Pragas e doenças de cultivos amazônicos. Belém: Embrapa Amazônia Ocidental. 379p.

Silva, A.G., 2010. Dinâmica populacional de mosca-negra-doscitros (Aleurocanthus woglumi Ashby, 1915) em pomares de citros em sistema agroflorestal e monocultura. Dissertação (Mestrado em Agronomia) - Faculdade de Ciências Agrárias e Veterinárias, Universidade Estadual Paulista, Jaboticabal. 79p.

\section{Como citar este artigo:}

Silva, A.G., P.R.S. Farias, A.L. Boiça Junior \& B.H.S. Souza, 2011. Mosca-Negra-dos-Citros: Características Gerais, Bioecologia e Métodos de Controle dessa Importante Praga Quarentenária da Citricultura Brasileira. EntomoBrasilis, 4(3): 85-91. www.periodico.ebras.bio.br/ojs
Silva, A.G., A.L. Boiça Junior, P.R.S. Farias \& J.C. BARBOSA, 2011a. Infestação da mosca-negra-dos-citros em pomares de citros em sistema de plantio convencional e agroflorestal. Revista Brasileira de Fruticultura, 33: 53-60.

Silva, A.G., A.L. Boiça Junior, P.R.S. Farias, N.E.L. Rodrigues, B.S. Monteiro \& N.A. Santos, 2011b. Influência de fatores abióticos na infestação de mosca-negra-dos-citros (Aleurocanthus woglumi Ashby) em plantio de citros em sistema agroflorestal no estado do Pará. EntomoBrasilis, 4: 01-06.

Summy, K.R., F.E. Gilstrap, W.G. Hart, J.M. Caballero \& L. Saenz, 1983. Biological control of citrus blackfly (Homoptera: Aleyrodidae) in Texas. Environmental Entomology, 12: 782786.

Recebido em: 18/03/2011

Aceito em: 11/06/2011

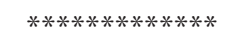

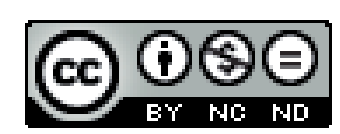

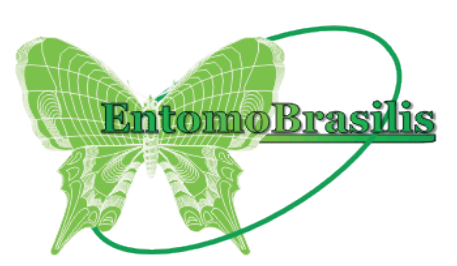

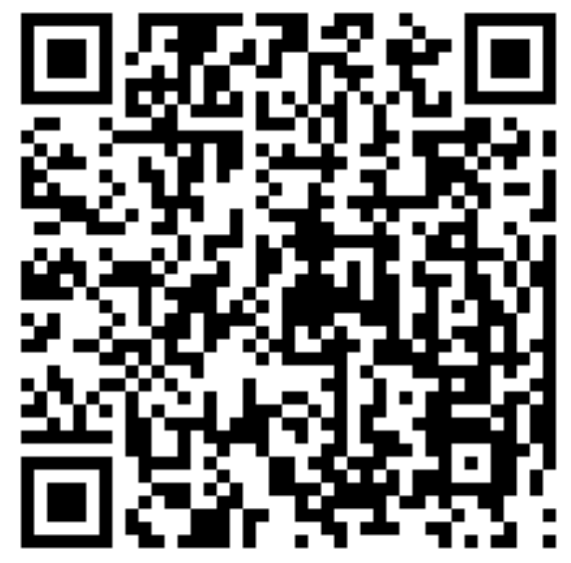

